\title{
Harnessing Public Institutions for Labour Law Enforcement
}

\author{
Embedding a Transnational Labour Inspectorate within the ILO
}

\author{
Antonio Garcia-Muñoz Alhambra ${ }^{1}$ \\ Research Fellow at Goethe University, Frankfurt am Main, Germany \\ Garcia-MunozAlhambra@jur.uni-frankfurt.de
}

\author{
Beryl Ter Haar ${ }^{2}$ \\ Assistant Professor European and international labour law and academic \\ coordinator Adv LL.M Global and European Labour Law at Leiden \\ University, the Netherlands \\ b.p.ter.haar@law.leidenuniv.nl
}

1 Currently Research Fellow at Goethe University (Frankfurt am Main) and working in the European Centre of Expertise, the author holds a PhD in Law for the University of Castilla-La Mancha (Spain) on European Union Collective Bargaining at sectoral level. He has done research on different topics of collective labour law and European social law and has published articles on topics such as European collective bargaining, Global Framework Agreements, Labour law and ecology, European Labour law or labour law reforms in Spain during the crisis in international, Spanish and Italian journals. He has published his $\mathrm{PhD}$ in 2017 with Bomarzo. He has taught Labour law, equality and employment policies and Public Employment relations in Castilla-La Mancha and post-doctoral courses in Poland, Germany and Spain on topics related to transnational labour law developments.

2 Assistant Professor and Academic-Coordinator for the advanced master programme Global and European Labour Law at Leiden University. Her research focuses on new developments in global and European labour law, including the issue of corporate social responsibility (CSR) and forms of transnational private regulation. She has presented her research at many international conferences, including YRS, ILERA, IREC, ISL\&SSL, LLRN, Marco Biagi Conference, CES, EUSA, ILPC, etc. Her research has been published in national (TRA, AR, TAO, and NJB) and international journals (e.g. ELJ, IJCLL\&IR, ELLJ, EJSL, and JESP). She is holder of the 2011 Marco Biagi Award (together with Atilla Kun and Antonio Garcia Munoz Alhambra), and the the Levenbach-price for best international publication in labour law. She is co-initator and chair of the Hugo Sinzheimer Moot Court Competition in European labour law. 


\begin{abstract}
Attila Kun ${ }^{3}$
Associate Professor, Head of Department (Department of Labour Law and Social Security), Károli Gáspár University, (KRE) Faculty of Law, Budapest, Hungary \& Associate Professor, National University of Public Service (NKE), Faculty of Political Sciences and Public Administration, Institute of Human Resources, Budapest, Hungary.

kun.attila@kre.hu
\end{abstract}

\begin{abstract}
The paper explores how to integrate a Transnational Labour Inspectorate ('TLI') dealing with transnational private instruments of Multinational Enterprises ('MNEs') into the International Labour Organization ('ILO'). After exploring monitoring initiatives with roots in public international organizations, we will argue that from an international law perspective on international legal personality such activities can be justified. Under the qualification of 'subject normation', as we dub these activities, we will argue that the ILO is the best situated locus to embed a system to inspect commitments MNEs voluntary adhere to in their CSR strategies, including Global Framework Agreements. Finally, we explain how the TLI as we envisage it could fit within the existing system of enforcement and compliance monitoring of the ILO.
\end{abstract}

\title{
Keywords
}

labour inspection - CSR - monitoring - ILO - global framework agreements - public organizations - international legal personality - ILP - Multinational Enterprises - MNEs

3 Associate Professor in labour law and the Head of the Department of Labour Law and Social Security at the Károli Gáspár University (KRE), Faculty of Law, Hungary (Budapest). He is also a part-time Associate Professor at the National University of Public Service (NKE), Institute of Human Resources. He is a member of the MTA (Hungarian Academy of Sciences) - PTE Research Group of Comparative and European Employment Policy and Labour Law. He is the national professional coordinator of the Hungarian Labour Advisory and Dispute Settlement Service (MTVSZ) and a registered advisor / mediator in the field of industrial relations in Hungary. He is a member of several academic networks (e.g.: Advisory Committe of the Labour Law Research Network, LLRN; Hungarian Labour Law Association; Academic network on the OECD Guidelines for Multinational Enterprises; Organising Committee of the Hugo Sinzheimer Moot Court Competition; national coordinator of the ISLSSL's Hungarian youth section etc.). 


\section{Introduction}

With the increase in awareness of multinational enterprises ('MNEs'), and their attention to corporate social responsibility ('CSR'), ${ }^{4}$ the call for independent, reliable and credible monitoring of their policies, often expressed through transnational private initiatives such as codes of conduct and global framework agreements, ${ }^{5}$ has increased as well. ${ }^{6}$ In this context we introduced in 2013 the idea for a transnational labour inspectorate (TLI). ${ }^{7}$ We proposed that this TLI should focus on the monitoring of MNEs' CSR policies in addition to national labour inspection activities monitoring compliance with national laws. Furthermore, we suggested that such a" TLI system should be facilitated by an international organization, preferably the International Labour Organization ('ILO'), in order to secure its independence and enhance its credibility. This article follows up on the 2013 paper and will argue that the momentum to set up such a system is ripening, alongside perception of the legitimacy of an international organization undertaking this role. Accordingly, we will indicate how such a TLI system could fit within the ILO's existing supervisory and monitoring activities.

The structure of the paper is as follows. In section 2 we will elaborate on the need for a TLI, briefly recap our proposal for a TLI, and discuss some similar ideas related to the functions of the ILO. In section 3 we describe and analyse existing and proposed monitoring initiatives that have some resemblance to our TLI proposal, in particular because these initiatives include some form of inspection and/or have a public root via an international organization. In section 4 we will elaborate on the question of the legitimacy of international

4 See for more in-depth accounts of this development, eg Niklas Egels-Zandén, 'TNC Motives for Signing International Framework Agreements: A Continuous Bargaining Model of Stakeholder Pressure' (2009) 84 Journal of Business Ethics 529; Isabelle Schömann et al, Codes of conduct and international framework agreements: new forms of governance at company level (Eurofound Report, 2008).

5 Konstantinos Papadakis, Shaping Global Industrial Relations. The Impact of International Framework Agreements (Palgrave McMillan, 2011).

6 See Kevin Kolben, 'Transnational Labor Regulation and the Limits of Governance' (2011) 12(2) Theoretical Inquiries in Law 403; André Sobczak. 'Codes of Conduct in Subcontracting Networks: A Labour Law Perspective' (2003) 44 Journal of Business Ethics 225; Lone Riisgaard, 'International Framework Agreements: A New Model for Securing Workers Rights?' (2005) 44(4) Industrial Relations 709; Guiseppe Casale, The Effectiveness of Labour Law And The Role of Labour Inspection (General Report XX World Congress ISL\&SSL, 2012).

7 García-Muñoz Alhambra, Manuel A, Beryl ter Haar and Attila Kun, 'Independent monitoring of private transnational regulation of labourstandards: A feasible proposition for a "transnational labour inspectorate" system?' in Edoardo Ales and Iacopo Senatori (eds), The Transnational Dimension of Labour Relations: a New Order in the Making?(G Giappichelli, 2013) 254. 
organizations to adopt rules, including monitoring systems, for MNEs, an activity we label 'subject normation'. This question is closely related to the acceptance of international legal personality for MNEs, the exploration of which is therefore part of this section. Section 5 concludes with an elaboration on how our idea for a TLI system fits within the ILO's supervisory and monitoring activities.

In this article we use the terms transnational or supranational to refer to those regulatory devices, institutions or enterprises that operate, or are designed to operate, in more than one nation State and consequently affect more than one national legal order. Finally, we refrain from engaging in an analysis of the political feasibility of our proposal. The aim of this article lies with illustrating and analysing the factual need for a TLI system and how this could fit within the ILO's supervisory and monitoring activities from a legal-technical point of view.

2

\section{The Need for a Publicly Rooted System to Monitor Transnational Private Labour Initiatives}

To put our proposal in context, a few words must be said about the need for a publicly rooted TLI system in order to create more independent, reliable and credible monitoring of transnational private labour initiatives ('TPLIs'), like MNEs' Codes of Conducts and GFAs.

TPLIs have emerged since the 1990s, in order to fill a regulatory gap between national and international public labour law regulations. They are designed to regulate the behaviour of transnationally operating economic actors, especially MNEs. ${ }^{8}$ These TPLIs differ in many aspects, such as their content, the level of stakeholders' involvement, etc. ${ }^{9}$ They have in common that there are questions regarding their credibility. ${ }^{10}$ Catastrophes like the collapse of the Savar building at the Rana Plaza in Bangladesh with more than 1100 workers dead and approximately 2500 workers injured, ${ }^{11}$ or persisting messages about the high number of deadly work accidents in Qatar in preparation for the 2022

8 See for an account of their emergence, among others, Papadakis, above n 2, 3-7.

9 See for a comparative analysis of the form, content and involvement of stakeholders, Antonio García-Muñoz Alhambra, Beryl ter Haar and Attila Kun, 'Soft on the Inside, Hard on the Outside: An Analysis of the Legal Nature of New Forms of International Labour Law' (2011) 4(27) International Journal of Comparative Labour Law and Industrial Relations 337.

10 Kolben, above $\mathrm{n} 3$.

11 See in general at the website of the ILO: <https:/www.ilo.org/global/topics/geip/ WCMS_614394/lang--en/index.htm>. See also: Motoko Aizawa and Salil Tripathi, 'Beyond 
FIFA World Cup, ${ }^{12}$ confirm scepticism about the effectiveness of TPLIs. Hence, in the academic literature, a lot of research has been conducted about the effectiveness of these initiatives. ${ }^{13} \mathrm{~A}$ key concern in this research is how to hold MNEs, especially brand companies, accountable for misconduct taking place in their value chain. ${ }^{14}$ The majority of this research, unfortunately, confirms earlier scepticism as they find that these initiatives are not very effective in terms of providing better protection for workers. A problem often highlighted with respect to the application of TPLIs is the lack of serious and effective monitoring systems. ${ }^{15}$

In response to the scepticism, but also learning from good practices, initiatives to improve the effectiveness of TPLIs are being developed. An important element of such initiatives is the concept of due diligence ${ }^{16}$ which requires MNEs to develop policies along their supply chain to improve compliance with human rights, including fundamental labour rights. ${ }^{17}$ More specifically,

Rana Plaza: Next Steps for the Global Garment Industry and Bangladeshi Manufacturers' (2016) 1(1) Business and Human Rights Journal 145, 145.

12 ITUC, The case against Qatar, host of the FIFA 2022 World Cup (ITUC Special Report, 2014) 28; Jonathan Liew, 'World Cup 2022: Qatar's workers are not workers, they are slaves, and they are building mausoleums, not stadiums', The Independent (London) October 3, 2017. See also: Beryl ter Haar, 'The FIFA 2022 World Cup and labour rights - seizing the moment for labour law reforms in Qatar' (2018) 5(1) Kutafin University Law Review 139.

13 See eg Richard M. Locke, The Promise and Limits of Power. Promoting Labor Standards in a Global Economy (Cambridge University Press, 2013); Christina Niforou 'International Framework Agreements and Industrial Relations Governance: Global Rhetoric versus Local Realities' (2012) 50(2) British Journal of Industrial Relations 359; Pamela K. Robinson, 'Do Voluntary Labour Initiatives Make a Difference for the Conditions of Workers in Global Supply Chains?' (2010) 52(5) Journal of Industrial Relations 561; Dong Hoang and Bryn Jones, 'Why do corporate codes of conduct fail? Women workers and clothing supply chains in Vietnam' (2012) 12(1) Global Social Policy 67.

14 See eg Aukje van Hoek and Frank Hendrickx, International private law aspects of dispute settlement related to transnational company agreements: final report (European Commission, 2009); Nicolas Bueno, 'Multinational Enterprises and Labor Rights: Concepts and Implementation', in Janice Bellace and Beryl ter Haar (eds), Research Handbook on Labour, Business and Human Rights Law (Edward Elgar) (forthcoming).

15 See above, $\mathrm{n} 3$.

16 A concept that is elaborately developed by the OECD: OECD, Due Diligence Guidance for Responsible Business Conduct (30 May 2018) <www.oecd.org/investment/due-diligenceguidance-for-responsible-business-conduct.htm $>$.

17 Anne Trebilcock, 'Due diligence on labour issues - Opportunities and limits of the UN Guiding Principles on Business and Human Rights' in Adelle Blackett and Anne Trebilcock (eds), Research Handbook on Transnational Labour Law (Edward Elgar, 2015) 93; Attila Kun, 'How to Operationalize Open Norms in Hard and Soft Laws: Reflections Based on Two Distinct Regulatory Examples' (2018) i International Journal of Comparative Labour Law \& Industrial Relations 23. 
due diligence can be defined as "the process through which enterprises can identify, prevent, mitigate and account for how they address their actual and potential adverse human rights impacts". ${ }^{18}$ How MNEs will do this and which human and labour rights they will adhere to is often expressed in their TPLI, eg a code of conduct. As such, TPLIs can be perceived as part and parcel of a complex due diligence process.

TPLIs frequently contain - harder or softer - provisions on implementation throughout the value chain, including mechanisms for compliance and monitoring. ${ }^{19}$ Since due diligence is often phrased in risk management, ${ }^{20}$ monitoring is an important aspect to gain trust in terms of the credibility of a MNE's CSR policy. However, there are many different forms of monitoring, varying from administrative audits ("ticking the boxes") to intensive actions, including stakeholder consultations, workers interviews, (unannounced) plant visits, etc. The more intensive and stringent the form of monitoring that is applied, the more seriously the monitoring is taken. The more serious the monitoring is, the more a MNE's CSR Policy will be respected by investors, clients and consumers, among others.

An important general normative expectation about the monitoring of TPLIs is that - ideally - it is done as independently as possible from the MNE; not only formally, but also in terms of its economic influence. ${ }^{21}$ The importance of independence of a monitoring entity is for example stressed in Article 6 of ILO Convention No 81, which deals with labour inspectorates. As we argued with the introduction of the TLI, such situation is in contrast with most of the current monitoring practices concerning TPLIs. ${ }^{22}$ Although transnational private monitoring cannot equal monitoring at national level, for example because the former is based on a network / multi-stakeholder attitude and market-based sanctions whereas the latter takes place in a hierarchical

18 OHCHR, Guiding Principles on Business and Human Rights (2011) principle $17<\mathrm{https}$ // www.ohchr.org/documents/publications/GuidingprinciplesBusinesshr_eN.pdf >; OECD, Guidelines for Multinational Enterprises (2011) ch 2, para 14 and ch 4, para $15<\mathrm{https} / / \mathrm{www}$ .oecd.org/daf/inv/mne/48004323.pdf>.

19 See eg Christian Welz, 'A Qualitative Analysis of International Framework Agreements: Implementation and Impact', in Konstantin Papadakis (ed), Shaping Global Industrial Relations, the Impact of International Framework Agreements (Palgrave MacMillan, 2011) 38-6o.

20 See Bueno, above n 11. See also Björn Fasterling, 'Human Rights Due Diligence as Risk Management: Social Risk Versus Human Rights Risk' (2017) 2 Business and Human Rights Journal 225, 226.

21 See Sobczak, above n 3.

22 See García-Muñoz Alhambra, above n 4, 265. 
setting with the use of public, mainly negative, sanctions. ${ }^{23}$ With our TLI proposal we aimed to introduce a form of monitoring as independent as possible, particularly via a "public root".

In short, the TLI system we proposed includes the following basic elements. ${ }^{24}$ The most important element is that the TLI should have a "public root". With this we mean that the TLI should be embedded in a public international organization. For several reasons, which we will elaborate on in the next paragraph and in section 5 , we consider the ILO as the international organization par excellence. Second, using the TLI is voluntary, which means it is a matter of discretionary decision by MNEs. This is due to the presumed lack of competence to make something like this mandatory. ${ }^{25}$ Thirdly, the monitoring is limited to what the MNEs are committed to in their TPLI; after all, this is what they want to monitor as seriously as possible. Furthermore, we proposed a "protocol" to ensure the independence and quality of the monitoring by the TLI. ${ }^{26}$ This protocol should address issues such as the selection of the TLIinspector which will lead the monitoring; the powers of the TLI; the composition of the MNE's specific TLI-committee; the monitoring procedures; the access to all parts of the MNE; and the form and enclosure of the outcome of the monitoring ('the TLI-report'). In addition, we considered aspects such as exclusion of the liability of the ILO and TLI in case a catastrophe happens despite the monitoring; payment of a fee by the MNE to cover the costs of the monitoring by the TLI; and the regularity of the monitoring. ${ }^{27}$

More particularly with respect to the role of the ILO, we envisaged the Organization to provide and maintain a list of accredited independent 'transnational labour inspectors'. These inspectors will be also trained by the ILO especially on issues generally found in the TPLIs of MNEs. MNEs voluntary opt for monitoring by the TLI. Once the MNE has opted for monitoring by the TLI, the MNE can select an inspector from the ILO's list of accredited inspectors. Led by the inspector, in collaboration with the MNE, the full monitoring body is comprised according to the rules and procedures set out in the above described protocol. More concretely, this means that the role of the ILO is limited to providing the list of inspectors, training the inspectors, and managing administration concerned with the participation of the MNE in the TLI-system. As such,

\footnotetext{
$23 \quad$ Ibid 258.

24 Ibid $275^{-77}$.

25 We will eleborate on this in sections 4 and 5 .

26 García-Muñoz Alhambra, above n 4, 277-81.

27 Ibid $277-83$.
} 
it is a purely facilitating role based on the expertise and activities already common to the ILO.28

As indicated, we will here also elaborate on the argument to have a public root with the ILO. In our previous paper we draw inspiration from doctrinal proposals by, among others, Hepple, ${ }^{29}$ Van Opijnen and Oldenziel, ${ }^{30}$ Pires, ${ }^{31}$ and Arrigo, Casale and Fasani. ${ }^{32}$ All of them make some link to the ILO. More recently, Van der Heijden and Zandvliet made an even stronger statement arguing that 'institutionally, the ILO should engage more directly with businesses and use its authoritative role to strengthen supply-chain bargaining.'33 Accordingly, they promote the idea of an "international factory inspectorate, which could play a more assertive role than current ILO missions". ${ }^{34}$ To support their idea they refer to a similar, already existing inspection, namely the International Atomic Energy Agency, which has a mandate to carry out site visits at its Member States' nuclear facilities. ${ }^{35}$ Furthermore, Van der Heijden and Zandvliet emphasize that, among its existing supervisory mechanisms, the ILO has the option to employ a Commissions of Inquiry and Direct Contact Missions to conduct fact-finding operations. These mechanisms have also been used in the

28 Since it is one of the aims of this paper to stipulate this, we will elaborate more on this in the last section.

29 Who stressed the need to set up "an international conciliation and arbitration service to resolve disputes between governments, TNCs and workers involving the alleged violation of rights under ILO conventions, bilateral treaties, corporate codes and international collective agreements." Bob Hepple, Labour Laws and Global Trade, (Hart Publishing, 2005).

30 Who put forward the ambitious idea for the establishment of a specific non-judicial monitoring authority at EU-level, which should be equipped with a mandate to investigate, sanction and provide remedies for abuses. Marjon van Opijnen and Joris Oldenziel, Responsible Supply Chain Management, Potential success factors and challenges for addressing prevailing human rights and other CSR issues in supply chains of EU-based companies, (European Union, 2011).

31 Who promotes a broad understanding of the intervention by the labour inspector creating a "social push" through legal, managerial and technological advancement (on which we built the TLI's broad mandate). Roberto Pires, 'Labour inspection and development: some reflections' (Working Paper No 9, ILO, 2011).

32 Who stressed that great strength of the labour inspectorate lies in thousands of sworn in public servants, (on which argument we built the need for a publicly rooted form of monitoring of TPLR, like the TLI) Gianni Arrigo, Giuseppe Casale and Mario Fasani, 'A Guide to Selected Labour Inspection Systems (with Special Reference to OSH)' (Working Paper No 10, ILO, 2011).

33 Paul van der Heijden and Ruben Zandvliet, 'Enforcement of Fundamental Labor Rights The Network Approach: Closing the Governance Gaps in Low-Wage Manufacturing Industries' (Policy Brief, The Hague Institute for Global Justice, 2014) 10.

34 Ibid.

35 Regulated in Title XII Agency Safeguards of the Statute of the IAEA. 
past, albeit as a last resort only. ${ }^{36}$ These interventions are of a more political character than the activities of labour inspectors. As such, an international inspectorate could be more proactive than the current ILO mechanisms.

Another advantage they highlight is that such an international inspectorate could focus "on 'invisible' sectors that are not on the CSR radar" ${ }^{37}$ Van der Heijden and Zandvliet conclude with the argument that such an "international factory inspectorate" could be an interesting "addition to the ILO toolkit rather than an alternative to existing public or private inspections". 38

This idea of Van der Heijden and Zandvliet and our idea for a TLI have strong similarities in the way that each seeks a role for the ILO. In the context of this paper, the idea of Van der Heijden and Zandvliet is particularly interesting because of how they compare and relate this to the ILO's supervisory mechanisms. However, they do not take this idea as far as indicating how it fits with the general role of the ILO being an international organization, nor do they specify how a form of a TLI can be embedded in the existing machinery of the ILO. The main aim of our contribution though is to do exactly that. Before we will elaborate on this (see section 5), we will explore some existing monitoring initiatives with public roots (section 3 ) and assess to what extent the ILO could embed a TLI for MNEs given the role and competence of international organizations (section 4).

\section{3}

\section{Selected Examples of 'Transnational' Monitoring with a Public Root}

In this section we analyse some existing forms or ideas of transnational monitoring of labour standards with a public root, ie a link to an international organization. These examples are very diverse (and often immature), but they have at least one common feature: by hook or by crook, they aim to lift up the monitoring function to a new transnational level with the involvement of some form of public authority.

$36 \quad$ See Commission of Inquiry for examples. One of the last Col's the ILO Governing Body has appointed deals with allegations of violations of labour standards by the Bolivarian Republic of Venezuela. See <www.ilo.org $>$.

37 See for a similar conclusion about the focus of CSR Chikako Oka, 'Evaluating a Promising Model of Non-State Labour Regulation: The Case of Cambodia's Apparel Sector', in Deidre McCann et al (eds) Creative Labour Regulation. Advances in Labour Studies (Palgrave Macmillan, 2014) 259.

38 Van der Heijden and Zandvliet, above n 31, 10-11. 
More specifically, the following initiatives are analysed: three initiatives by the European Union [the short-lived European Monitoring Platform ('EMP'), the proposed and widely discussed Optional Legal Framework ('OLF') for Transnational Company Agreements ('TCAs'), and the European Labour Authority ('ELA' - which is still under construction)]; the debates within the UN Human Rights Council for a binding instrument on 'business and human rights', connected to which an independent monitoring body has also been contemplated; and the Bangladesh Accord, which includes factory inspections with some engagement of the ILO. Lastly, we will address some forms of monitoring by OECD NCPs.

Analysing what kind of monitoring these initiatives have set up and how these monitoring activities are embedded in (or involve) international organizations will help us to identify the strengths and shortcomings of what already exists and reinforces our arguments on the need for a publicly rooted TLI. Moreover, it will enable us to understand how the ILO could (and should) embed a TLI-system.

\subsection{Monitoring initiatives by the European Union}

Since the late 1990s the EU has been remarkably active in adopting policies addressing MNEs in the context of CSR and Human Rights. ${ }^{39}$ Three selected initiatives which embrace certain specific mechanisms to transnationally (or actually supranationally) monitor labour standards and/or activities of MNEs are analysed: 1) the European Monitoring Platform; 2) the Optional Legal Framework for transnational company agreements; and 3) the European Labour Authority.

\subsubsection{European monitoring platform}

In 1999 the EU adopted a Code of conduct for European enterprises operating in developing countries which aim was to create a European enforcement mechanism for codes of conduct. In Article 14 of the Resolution that envisaged the abovementioned code, the European Parliament 'call[ed] on the Commission to study the possibility of setting up a European Monitoring Platform [...] in close collaboration with the social partners, NGOs from North and South, and representatives of indigenous and local communities' 40 To this end,

39 See for an elaborate overview of the activities of the EU: Beryl ter Haar and Attila Kun, 'The EU's CSR policy in a global and national context' in Janice Bellace and Beryl ter Haar (eds) Research Handbook on Business, Labour and Human Rights Law (Edward Elgar) (forthcoming).

40 European Parliament - Resolution on EU Standards for European Enterprises operating in Developing Countries: towards a European Code of Conduct OJ [1999] C104/14 para 14. 
special rapporteurs were to be appointed and annual hearings were to be held in the European Parliament, for which 'social partners and NGOs from the South and the North' would be invited until the EMP was established. ${ }^{41}$ The EMP - as a genuine institution - has never been realised, but, for example a Special Meeting on "Standard Setting by European Enterprises in Developing Countries" took place in the European Parliament on 22 November 2000.42 Two companies were invited to attend this meeting for scrutiny - Adidas did not show up. ${ }^{43}$ The yet to be established EMP would have consisted mostly of 'independent experts in addition to a board of representatives from the European business and industry sector and international trade unions, environmental and human rights NGOs, including representatives from the South.'44

Furthermore, the EMP 'would receive reports from business and industry about their compliance with international standards and codes of conduct submitted to the Monitoring Platform voluntarily or after request; it would select case studies on the basis of the information submitted; it would evaluate the validity of the complaints and the reports submitted on the basis of agreed upon auditing procedures for verification; auditing mechanisms would provide important factual and experiential background for developing international law in relation to corporate conduct; and it would publicise the results of the inquiries on an annual basis. ${ }^{\prime 4}$ The EMP was to be equipped with a complaint procedure and some auditing procedures.

Optional legal framework for transnational company agreements

Debates on what could help strengthen and enforce transnational company agreements (TCAs) go back many years. The idea of an optional legal framework at European level entailing the creation of joint negotiating bodies which facilitate the conclusion of transnational collective agreements is among the related proposals and was raised for the first time by the European Commission in one of its work programmes, namely the Social Agenda of $2005 .{ }^{46}$

\footnotetext{
41 Ibid.

42 See Clean Clothes Campaign, Inside a National CCC (October 2007) <https://archive .cleanclothes.org/news/insidea-national-ccc-united-kingdom-clean-clothes-newsletter -nr24/551-ccc-report-on-eu-parliament-meeting.html>.

43 Ibid.

44 European Parliament - Explanatory Statement of the Report on EU standards for European Enterprises operating in developing countries: towards a European Code of Conduct [1998] A4-0508/98, recommendation 2.

45 Ibid.

46 European Commission, 'Communication from the Commission on the Social Agenda' (Statement, European Commission, 2005).
} 
Although the proposal has not been adopted, the idea is not dead. It is still on the agenda of the European Parliament which has issued several resolutions on the topic. ${ }^{47}$ Several reports have been written about the OLF by experts, ${ }^{48}$ and the European Trade Union Confederation ('ETUC') and affiliates have continued to work on it. ${ }^{49}$

Although monitoring as such is not part of most of these proposals and reports, the 2016 proposal by the ETUC suggests that the OLF should provide two particular tools. The first tool is an Alternative Dispute Resolution ('ADR') mediation mechanism at the European level. This ADR should be accessible to signatory parties only and is 'to be used when the internal procedure set up by the TCA itself doesn't succeed in solving the dispute. ${ }^{50}$ Moreover, as part of its goals to realise the creation of an OLF, the ETUC has set four actions for itself. The fourth action is to 'continue discussing and lobbying the European Commission [as well as pushing] the Commission to support the [ETUC's] work on the proposals for the mediation and registration mechanisms, as a starting point for the development of an OLF'.51

\subsubsection{European Labour Authority}

The European Labour Authority was announced by President Juncker in his 2017 State of the European Union speech. ${ }^{52}$ The aim of the ELA is to ensure that EU rules on labour mobility, especially in the context of the posting of

47 See eg European Parliament - Cross-border collective bargaining and transnational social dialogue [2013] 2012/2292 INI.

48 See eg the so-called 'Ales report': Edoardo Ales, Samuel Engblom, Teun Jaspers, Sylvaine Laulom, Silvana Sciarra, André Sobczak and Fernando Valdés Dal-Ré, 'Transnational Collective Bargaining. Past, Present and Future' (Report, European Commission, 2006); Silvana Sciarra, Maximilian Fuchs, André. Sobczak, 'Towards a Legal Framework for Transnational Company Agreements' (European Trade Union Confederation, 2014).

49 See ETUC Resolution Proposal for an Optional Legal Framework for transnational negotiations in multinational companies, (adopted by the ETUC Executive Committee, 11-12 March 2014) <https://www.etuc.org/en/document/etuc-resolution-proposal-optional -legal-framework-transnational-negotiations-multinational>.

50 ETUC Resolution Roadmap on Transnational Company agreements: Progressing towards an Optional Legal Framework (adopted by the ETUC Executive Committee, 30 August 2016) <https://www.etuc.org/en/document/etuc-resolution-roadmap-transnational -company-agreements-progressing-towards-optional>.

$51 \quad$ Ibid.

$5^{2}$ See further, Éva Lukacs, 'European Labour Authority — The guardian of posting within the EU?' (2018) 1 Hungarian Labour Law E-Journal <www.hllj.hu/20181a.htm>. 
workers, are being enforced in a fair, simple and effective way. The ELA 'should be up and running in 2019 and reach its full operational capacity by $2024^{\prime} \cdot{ }^{\prime 3}$

In its impact assessment, the European Commission envisaged three roles for the ELA, referred to as "options". ${ }^{4}$ Option 1 (support) constitutes a "lighttouch" approach as it focuses on functions of analytical and technical support to existing structures and tools. Option 2 (operational role) goes one step further by mandating ELA with the functions of promoting common technical standards, increasing cooperation between national authorities, coordinating and logistically supporting joint cross-border inspections etc. ${ }^{55}$ The third option ("supervisory"; or "mandatory") depicts "a more thorough EU-level integration of certain functions", going as far as a specialised European Inspection Corps. ${ }^{56}$

Although the original proposal envisaged a genuine "European inspection and enforcement body, ${ }^{57}$ the emerging actual set up seems to represent a considerable softer and meagre version. ${ }^{58}$ The focus of the ELA that is currently materializing is on assistance to the national administrations only, which seems kind of a combination of Options 1 and 2. Furthermore, Member States will only take part in ELA's activities on a voluntary basis, instead of mandatory as set out in Option 3. However, the creation of the ELA will suppose the establishment of a permanent structure providing support to national authorities, which itself has already a high potential to coordinate inspection at transnational level. ${ }^{59}$

53 European Commission, European Labour Authority <ec.europa.eu/social/main.jsp?catId $=1414$ \&langId=en $>$. On 24 May 2019 the Council adopted the Regulation establishing the ELA: Council of the European Union, 'European Labour Authority: Council adopts founding regulation' (Press release, 13 June 2019) <www.consilium.europa.eu/en/press/ press-releases/2019/06/13/european-labour-authority-council-adopts-founding -regulation/>.

54 European Commission, 'Impact Assessment accompanying the document Proposal for a Regulation of the European Parliament and of the Council establishing a European Labour Authority' (Working Document Impact Assessment, 2018) 68.

Cf European Commission, 'Commission Staff Working Document Impact Assessment Accompanying the Document Proposal for a Regulation of the European Parliament and of the Council Establishing a European Labour Authority' (Working Document Impact Assessment, 13 March 2018) <eur-lex.europa.eu/legal-content/ET/ALL/?uri=SWD\%3A2018 $\% 3$ Aoo68\%3AFIN>.

56 Ibid.

57 European Commission, 'President Jean-Claude Juncker's State of the Union Address 2017' (Press Release, 13 September 2017) <europa.eu/rapid/press-release_SPEECH-17-3165_en .htm>.

58 See Council of the European Union, Provisional agreement on a Regulation establishing a European Labour Authority between the Romanian Presidency of the Council and the European Parliament, [2019] <www.consilium.europa.eu/>.

See for details European Commission, above $\mathrm{n} 5$. 


\section{2}

\section{Monitoring initiatives at the transnational level}

\subsection{1}

UN Human Rights Council - OEIWG

On 26 June 2014, during its $26^{\text {th }}$ session, the United Nations ('UN') Human Rights Council adopted Resolution 26/9 by means of which it was decided to establish an open-ended intergovernmental working group ('OEIWG') on transnational corporations and other business enterprises with respect to human rights, whose mandate shall be to elaborate an international legally binding instrument to regulate, in international human rights law, the activities of transnational corporations and other business enterprises. ${ }^{\prime 60}$ During the deliberations of the OEIWG, several NGOs raised the need for an "independent monitoring body". ${ }^{61}$ In its first session in 2015 , some NGOs called for 'effective bodies of enforcement, such as a committee for compliance oversight or a public centre for control of transnational corporations.' ${ }^{62}$ In October 2018, during its fourth session, the OEIWG discussed a so called zero draft entitled 'legally binding instrument to regulate, in international human rights law, the activities of transnational corporations and other business enterprises' ${ }^{63}$ Annexed to the zero draft on the Legally Binding Instrument (LBI) is a zero draft Protocol which deals with the implementation of the LBI. ${ }^{64}$ The zero draft on the LBI itself does not foresee the establishment of vigorous bodies at the international level, such as a court or monitoring mechanism although the Protocol does.

The most interesting form of monitoring, in our opinion, is found in Article 5 of the Protocol, which provides that the "States Parties to the present Protocol shall grant to the National Implementation Mechanism [NIM] competence to conduct reviews on the implementation of due diligence obligations in accordance with Article 9 of the [LBI]". To do these reviews, the NIM would have several competences, among which "to conduct visits and inspections to the

6o UN Human Rights Council, Elaboration of an international legally binding instrument on transnational corporations and other business enterprises with respect to human rights, 26th session A/HRC/RES/26/9 (2014).

61 UN Human Rights Council, Report on the first session of the open-ended intergovernmental working group on transnational corporations and other business enterprises with respect to human rights, with the mandate of elaborating an international legally binding instrument, $3^{\text {st }}$ session $\mathrm{A} / \mathrm{HRC} / 3_{1} / 5^{0}(2016)$.

62 Ibid.

63 Permanent Mission of Ecuador, Zero Draft Legally Binding Instrument To Regulate, In International Human Rights Law, The Activities Of Transnational Corporations And Other Business Enterprises (2018).

64 OHCHR, Zero Draft Protocol annexed to the LBI < www.ohchr.org/Documents/HRBodies/ HRCouncil/WGTransCorp/Session4/ZeroDraftOPLegally.PDF>. 
business [enterprise's] facilities, and conduct joint visits [and inspections] with other National Implementation Mechanisms and relevant authorities of the concerned State Party to monitor the implementation and follow up of due diligence plans or policies". ${ }^{65}$ Once a State Party has accepted the LBI, it automatically accepts the Protocol. Given the fact that the monitoring foreseen in Article 5 of the Protocol is obligatory (State Parties "shall"), it can be interpreted as underling that any genuine regulation of human rights in transnational setting, either public or private, needs to be accompanied with a proper monitoring mechanism.

\subsubsection{Accord on Fire and Building Safety in Bangladesh}

The Accord on Fire and Building Safety in Bangladesh was concluded immediately after the collapse of the Rana Plaza building on 24 April 2013. Over 220 companies signed the Accord, which has been renewed by the 2018 Transition Accord. ${ }^{66}$ The Accord is a legally binding agreement between global brands \& retailers and trade unions (including IndustriALL and UNI global unions). As Croucher et al note, "[the] Accord has been able to impose internationally recognised fire and building standards" and to "establish a relatively well-resourced body to undertake inspections including follow-ups".67 One of its key features is the "Independent safety inspections \& remediation program", which represents a form of transnational labour-related inspection scheme. In short, the system works as follows. The signing transnational companies classify their suppliers/subcontractors in three groups according to their production's volume. The classified suppliers/subcontractors must accept inspections in situ and are obliged to solve whatever problems may be detected. This obligation has a different intensity depending on the group where the supplier/ subcontractor has been classified. Those suppliers with a higher volume of production, belonging to "group 1" and "group 2", are subject to more intense inspections. This allows, on the one hand, making the inspections feasible, due to the huge number of existing suppliers and, on the other hand, put the pressure on the biggest suppliers, which are those with a stronger bargaining power and market share, to open the path in the improvement of health and safety conditions of the textile industry in Bangladesh. 68

\footnotetext{
65 Ibid art 5 , para 2.

66 The 2018 version of the Accord on Fire and Building Safety in Bangladesh can be found at the Accord's website: <bangladeshaccord.org/about $>$.

67 Richard Croucher, Mark Houssart, Lilan Miles and Philip James, 'Legal sanction, international organisations and the Bangladesh Accord' [2018] Industrial Law Journal.

68 Accord on Fire and Building Safety in Bangladesh, above n 63, art 8-11.
} 
The inspections are performed by a so-called "qualified Safety Inspector". This Inspector is designated by the Steering Committee. Important for the Inspector is that, besides being an expert on fire and building safety, he is independent of the company, trade union or factory he is inspecting. The Inspector selects a team to perform the inspections with. This team of inspectors elaborates reports on the suitability and compliance of the Inspections' programme and informs, when problems are detected, to the signatories of the agreement. This information may be published. To secure the enforcement of the Accord, the Steering Committee must make publicly available on a regular basis reports on the status of the Inspection programmes and some other information related, such as lists with the providers, etc. ${ }^{69}$

\subsubsection{Some forms of monitoring by OECD NCPs}

The OECD Guidelines for Multinational Enterprises constitute "a global framework for responsible business conduct covering all areas of business responsibility, including [...] employment and industrial relations"70 Countries adhering to the Guidelines are required to set up National Contact Points ('NCPs'). The NCPs have as task to promote the effectiveness of the guidelines, therefore their mandate provides, among other competences, to function as a platform for mediation and conciliation to resolve cases (known as "specific instances" ${ }^{71}$ of the alleged infringements of the Guidelines. The good offices of the NCPs might involve on-site visits and actual inspection of the situation, depending on, among others, the resources of the given NCP. ${ }^{72}$ Naturally, such good offices shall be consensual, resulting in a non-adversarial dialogue. ${ }^{73}$

NCPs are not per se about monitoring or inspection, but some NCP-cases can result in a monitoring plan involving the NCP. Furthermore, "some NCPs make it regular practice to follow up on recommendations they provide during

69 This information is available at the webpage of the Accord <bangladeshaccord.org/>. On the achievements of the Accord see also Jeffrey S. Vogt, "The Bangladesh Sustainability Compact: An Effective Tool for Promoting Worker's Rights? (2017) 5(4) Politics and Governance $80,87-88$.

70 OECD, above $\mathrm{n} 15$.

71 See at OECD, Specific instance handling under the OECD Guidelines for Multinational Enterprises $<$ mneguidelines.oecd.org/specificinstances.htm $>$.

72 OECD, Guide for National Contact Points on Structures and Activities (2019) < mneguidelines.oecd.org/ncps/>.

73 On the origins, development and functioning of the Guidelines see John G. Ruggie and Tamaryn Nelson, 'Human Rights and the OECD Guidelines for Multinational Enterprises: Normative Innovations and Implementation Challenges' (2015) 1 Brown Journal of World Affairs 99. 
specific instances". ${ }^{74}$ Such cases are reported from the UKNCP, the Swiss NCP, the French NCP. For instance, the Norwegian NCP notes that 'parties have expressed a wish for greater NCP involvement in follow-up, for instance to monitor whether the Guidelines are more effectively implemented by a company after the specific instance. ${ }^{75}$ Consequently, "[the] Norwegian NCP now advises parties to include more detailed provisions about the implementation of the parties' agreement as part of the follow-up in any mediated statement, including the [monitoring] role of the NCP". ${ }^{76}$

\subsection{Analysis}

The selected examples discussed above illustrate that the question of transnational monitoring has been present for some years in a number of projects and initiatives. Furthermore, transnational monitoring has been thought of as demanding some kind of institutional mechanism to overcome the shortcomings and specific problems of labour related issues at transnational level.

In this sense, initiatives like the EMP, the proposal for an OLF for transnational collective bargaining, the Protocol drafted by the working group of UN, and the OECD NCPs demand the development of some legal framework and institutional apparatus, either brand new or embedded in the institutional setting of international organizations (UN, OECD) or even the supranational legal order of the EU (for the EMP, the OLF and the ELA). The rationale behind all these initiatives is the will, or need, for some kind of an independent monitoring/auditing/inspection mechanism at transnational level. The will or need lies with the aim to overcome shortcomings identified in the existing (or nonexisting) legal framework to govern transnational labour standards and tools. Furthermore, these examples show that at EU level and within the UN, OECD, etc. The very idea of some kind of a transnational independent and publicly rooted monitoring/auditing/inspection mechanism has at least some political support.

A number of interesting features in the selected examples we have described in this section need to be highlighted here. The examples of the EMP, ELA and OECD NCPs are interesting since they have been (or were planned to be) set

\footnotetext{
74 OECD, Implementing the OECD Guidelines for Multinational Enterprises: The National Contact Points from 2000 to 2015 (Report, OECD, 2016) 58.

75 Ibid.

76 Ibid.
} 
up within a permanent structure, rather than an ad hoc body to be comprised when monitoring is needed. This enables these monitoring bodies to grow and improve their functioning, as can be seen by the OECD NCPs, which is the most mature body among these initiatives. Another interesting feature of the selected examples is that they vary in sort and range of monitoring activities they can undertake. However, in combination with the first feature (permanent body) we can see room for these activities to develop from, often, initially rather weak monitoring activities, such as operational and technical support, the exchange of information, to more structural forms of monitoring such as day-to-day cooperation routines, follow-up activities, and to more serious (or mature) forms of monitoring like inspections and dispute settlement which often takes place in the form of mediation. Even in the example of the Bangladesh Accord, which was set up as a temporary monitoring body (initially five years) and a specific task (the inspection of fire and building safety) development of the monitoring activities can be seen. What these examples have in common is a form of stability, which fosters the development of specialization and seriousness of the monitoring mechanisms.

Another feature that can be taken from these examples is that none of them came to life overnight. All seem to develop in baby steps, nonetheless, developments into maturity can be witnessed. Especially the development of the OECD NCPs monitoring follow up activities by the parties which they mediated a conflict is a striking example. Also the grow-model that seems to underpin the ELA is an interesting illustration. As already hinted at when we discussed the idea of Van der Heijden and Zandvliet, ${ }^{77}$ many of these initiatives have a pragmatic and problem-solving approach, rather than a political or politicized approach.

All of these examples have a public root in international organizations. The EMP, OLF and ELA (were supposed to) have roots within the EU institutional settings. The UN Human Rights Council's discussions envisage embedding of monitoring in national public organizations, rather similarly to the OECD NCPs. With the Bangladesh Accord we see an embedding of the ILO in the initiative envisaging an independent chair of the Steering Committee and at national level with the involvement of the Bangladeshi government concerning the development of the fire and building safety inspections. Moreover, the example of the Bangladesh Accord - and some other recent notable unique initiatives focusing on global supply chains, like the ILO's Better Work 
Programmes ${ }^{78}$ and the FIFA's independent Human Rights Advisory Board ${ }^{79}-$ clearly illustrate that collaborative (public-private mix), multi-stakeholder, compliance-enhancing governance mechanisms are a real option within the transnational field. ${ }^{80}$

Our takeaways from these examples for the embedding of the TLI-system we envisage within the ILO are the following. Stability is important as it fosters the development of specialization and seriousness of the monitoring mechanisms. This cannot be achieved overnight but needs time, as this develops in baby steps. Pragmatic hands-on problem-solving monitoring initiatives seem to be feasible, contrary to more politicized approaches to monitoring. Having a public root through embedding or involvement of in an international organization seems to be no problem, as long as there is a (political) willingness to create public-private structures. Altogether we can conclude that at transnational level there is room for (the further development of) the "third leg of government", ie monitoring. ${ }^{81}$ Before we turn to an elaboration on how this could and should be done by the ILO for the TLI, we take a more theoretical turn in order to explore from an international law's point of view the possibility to develop this "third leg of government" by directly setting up monitoring mechanisms for MNEs.

78 See for information about the ILO's Better Work Programmes at < betterwork.org/>. Part of the activities within the context of these programmes can be "factory assessments", ie an assessment of a factory's overall progress on meeting international standards and national laws. The assessment findings are coupled with the factory's own diagnosis of problems which combined will provide a fair and well-rounded picture of success, demonstrated progress and areas for continued improvement (or persistent problems). Eg the Better Work Programme for the ready-made garment and footwear industry in Vietnam. See at Better Work, Better Work Vietnam: Our Services <betterwork.org/where-we-work/ vietnam/bwv-our-services/>.

79 The representation of the UN softly ensures the 'public root'. See Fifa, Fifa Publishes Landmark Human Rights Policy (8 June 2017) < www.fifa.com/governance/news/y=2017/m=6/ news=fifa-publishes-landmark-human-rights-policy-2893311.html >.

8o See on this public-private mix Manfred Weiss 'International Labour Standards: A Complex Public-Private Policy Mix' (2013) 29(1) The International Journal of Comparative Labour Law and Industrial Relations 7; Ulrich Mückenberger, 'Hybrid Global Labour Law', in Roger Blanpain and Franck Hendrickx (eds), Labour Law Between Change and Tradition, Liber Amicorum Antoine Jacobs, (Kluwer, 2011) 99.

81 This refers to the idea that enforcement of labour law in general depends basically on state (public) action of detecting employers that breach the law, and such state actions basically have three 'legs': inspection, dispute-settlement (access to justice) and 'public campaigns to provide workers with information about their rights'. See eg Ravi Kanbur and Lucas Ronconi, 'Enforcement Matters: The Effective Regulation of Labor' (2018) 157(3) International Labour Review 331, 333. 


\section{ILP for MNEs and "Subject Normation" by International Organizations}

The aim of this paper is to indicate how the ILO could (and should) embed a TLI-system. Even though the role of the ILO is limited to facilitation and support and the TLI-system is something MNEs can opt voluntarily, from an international law perspective a TLI system raises the question of the extent of ILO competence. More generally, in the context of (international) human and labour rights law, the measures adopted by international organizations addressing MNEs directly are legally non-binding. The presumed reason for this is that international organizations lack legal competence to adopt legally binding measures, ${ }^{82}$ because MNEs are not subjects of international law. ${ }^{83}$ However, this is based on a rather outdated approach of international legal personality ('ILP') in which only states are considered subjects of international law. Since the 1960s, the view on ILP has changed significantly and consequently, it is no longer self-evident that MNEs lack ILP. In this section we elaborate on the extent to which MNEs are considered to have ILP and what this means for international organizations to adopt measures directly addressing MNEs. We will conclude with a reflection on what this means for the ILO to embed a TLIsystem as we propose.

\subsection{Inclusive approach on ILP}

When we review the literature on ILP we have to come to the conclusion that, similar to soft law, ${ }^{84}$ there are as many interpretations as there are scholars with theories and thoughts about this. ${ }^{85}$ Many of these scholars refer or build on the ideas of Friedmann. What is interesting about Friedmann's idea is that it keeps a close link between the role of international organizations and the

82 Cf Yarik Kryvoi, 'Enforcing Labor Rights against Multinational Corporate Groups in Europe' (2007) 46 Industrial Relations 2.

83 See in general Robin F. Hansen 'The International Legal Personality of Multinational Enterprises: Treaty, Custom and the Governance Gap' (2010) 10(1) Global Jurist.

84 M.A. García-Muñoz Alhambra, above $\mathrm{n} 6$.

85 See eg Hansen, above n 79; Janne E. Nijman, The Concept of International Legal Personality. An inquiry into the history and theory of international law (TMC Asser Press, 2018) 405, 455, with reference to A. Carty, Critical International Law: Recent Trends in the Theory of International Law (1991) 66(2) European Journal of International Law 1, in which Carty discusses Martti Koskenniemi, From Apology to Utopia. The structure of International Legal Argument (Cambridge University Press, 1989); Anne Peters, Beyond Human Rights. The legal status of the individual in international law (Cambridge University Press, 2016); and William T. Worster, 'Relative International Legal Personality of Non-State Actors' (2016) 42 Brook Journal of International Law 207. 
possibility to govern a "person" because it has (limited) ILP, which is exactly the connection we need for our proposal to embed the TLI within the ILO.

Friedmann's account of ILP actually starts with Leibniz' interpretation of ILP which was set in the Westphalian times, namely ILP was 'the prerogative of those whose "authority, then, is sufficiently extensive," to be called sovereign. ${ }^{86}$ For Leibnitz this was a person, not a State. ${ }^{87} \mathrm{~A}$ ruler was a person who could "count on sufficient freedom and power to exercise some influence in international affairs", eg "with armies or by treaties". ${ }^{88}$ Such a person had ILP. ${ }^{89}$ Having ILP meant that a ruler had powers or rights, as well as "the legal responsibility to use their authority" in accordance with international law. ${ }^{90}$ ILP conceptualized by Leibniz therefore held two concepts: a technical concept to indicate formal subjection to the law of nations and a substantial or material concept which added to the capacity to act responsibly and justly. ${ }^{91}$ As such, Leibniz' conceptualization is interesting with respect to MNEs, since, at least based on the Ruggie framework and the OECD's interpretation of due diligence, MNEs are expected to act responsibly and justly for as far as this is within the range of their capacity. ${ }^{92}$

In a way, Friedmann brings Leibniz' interpretation of ILP into the $20^{\text {th }}$ century when he, building on the works of, among others, Morgenthau, Lauterpacht and McDougal, reappraises ILP, in a pragmatical and functional manner. More particularly, Friedmann argued that ILP should be an "inclusive" concept requiring a re-ordering of the subjects of international law by embracing, next to States as principal subjects of international law, also international organizations and to a lesser extent private corporations and human individuals. ${ }^{93} \mathrm{In}$ Nijman's view Friedmann's approach to ILP, especially the consideration of the relationship between responsibility and justice, reflects a post-modern take on ILP. ${ }^{94}$ While over the course of time individuals and international

86 Nijman, above n 81, 77, with reference to Gottfried.W. Leibniz, Codex Juris Gentium diplomaticus, in the transl. of Patrick Riley (ed), Leibniz Political Writing (Cambridge University Press, 1989) 175 .

$87 \quad$ Nijman, above n 81, 77 .

88 Ibid $5{ }^{8}-59$.

89 Ibid 78 .

9o Ibid 79 .

$91 \quad$ Ibid.

92 As indicated above in section 2.

93 Wolfgang Friedmann, The Changing Structure of International Law (Cambridge University Press, 1964) ch 1, 6, 365-8.

Ibid 307. 
organizations have been recognized as subjects of international law, ${ }^{95}$ MNEs only hold "limited ad hoc subjectivity" to the extent that their transactions could be controlled by the norms of public law. ${ }^{96}$

In the context of human rights law, arguments have been made that given its purpose to guarantee certain 'inalienable levels of treatment and entitlement for all people, efficacy logically demands that the principles extend beyond obligations on States alone. ${ }^{97}$ De Jonge takes this one step further and argued that MNEs should be subjected "to mandatory standards of international law comparable to those which states are subject to". 98 She substantiates her arguments by elaborating on how MNEs could be brought under international law in similar ways as States are. ${ }^{99}$ To a certain extent this is already the situation, for example regarding norms of jus cogens, ${ }^{100}$ such as not to commit slavery. In her conclusions though, De Jonge recognizes that for the time being such would not be feasible. Inclusion of MNEs on equal footing as States implies that they also will be equally involved in the (international) standard setting processes. Smaller (and often poorer) States, but also NGOs (and for labour rights, trade unions) are very wary of the influence of MNEs. MNEs, in turn, apparently are not very keen on such an involvement either, seemingly out of fear and suspicion of being subjected to more regulations. ${ }^{101}$

Based on the above review we can conclude that there is a status quo that MNEs have limited ILP. More particularly, in the context of this paper - the monitoring of MNEs CSR policies - it is clear that MNEs have internationally recognized and promoted responsibilities. ${ }^{102}$ Since it is recognized that MNEs have responsibilities, arguments are made that international organizations could and should set standards and stipulate what kind of behaviour is expected from MNEs. ${ }^{103}$ Materially, De Jonge makes the most persuasive

95 Ibid 341. See also Alice de Jonge, Transnational Corporations and International Law. Accountability in the Global Business Environment (Edward Elgar 2011) 147-148.

96 Nijman, above n 81, 342 .

97 Adam McBeth, International Economic Actors and Human Rights (Routledge, 2010), 249. See for similar accounts: Nijman, above n 81 ; and Peters, above $n$ 81.

98 De Jonge, above n 92, 149 .

99 Eg on how the 1969 Vienna Convention on the Law of Treaties could be expanded to MNEs and how MNE Responsibility could be modeled on State Responsibility. Ibid $150-158$.

100 Cf ibid 150.

101 Ibid 209.

102 Cf Hansen, above n 79, 79; De Jonge, above n 92, 149; McBeth, above n 94, 249.

103 Cf De Jonge, above n 92, 149-150; Jose E Alvarez, 'Are Corporations Subjects of International Law' (2011) 9 Santa Clara Journal of International Law. 1, 31; and Adefolake Adeyeye, 'The Role of Global Governance in CSR' (2011) 9 Santa Clara Journal of International Law. 147 (esp 165-6 where she refers to this as 'global governance'). 
arguments for this: subjecting MNEs to (mandatory) "standards of international law would be to the benefit of both the global community and the individual TNC". ${ }^{104}$ MNEs would benefit as this would provide them with a legal back up against the pressure of often short term benefit oriented to shareholder demands in order to strive for long-term shareholder value, market stability and business sustainability. ${ }^{105}$ The global community would benefit from as this would support governments in host states 'to legislate at the local level in conformity with those [international] standards, without risk of being accused of breaching obligations imposed by trade and investment treaties. ${ }^{106} \mathrm{We}$ would like to add to this argument that this would also level the global market playing field to a certain extent, since the same standards would apply no matter where the business takes place. This is to the benefit of the MNE as it is clear what is expected wherever business is done and would benefit the host state by limiting the MNE to negotiate about these standards under the threat of taking the business elsewhere.

Turning back to the issue of the possibility for international organizations, and the ILO in particular, to set norms for MNEs we can conclude that there are formal as well as material arguments legitimizing this. To distinguish this kind of standard setting international organizations from what they do for States that possess full ILP, we would like to call this 'subject normation. The term 'subject' refers to the fact that the standard applies to entities that have been recognized as subjects for that particular standard. The term 'normation' refers to the aim of the standard to set a norm of expected behaviour by the recognized subjects. Although this may not create the strong duties international law can put on states, as underlined by Hansen ${ }^{107}$ and De Jonge, ${ }^{108}$ there is potential to legitimize the activities of international organizations to create the three legged-structure governments use to enforce compliance with labour law, ${ }^{109}$ and hence more room for a better embedding of a TLI system.

In this section we aim to explain how our proposal for a TLI system could, and should, be embedded within the ILO. To do so, we depart from the ILO's

\footnotetext{
104 De Jonge, above n 92, 149.

105 Ibid.

106 Ibid.

107 Hansen, above n 79, 79.

108 De Jonge, above n 92, 149 .

109 See above section 3 and $n$ 77.
} 
already existing tools and functions related to MNEs specifically. With this we will illustrate that many elements of our proposal — if not its overall idea are already (at least potentially) present to some extent within the ILO. In a second step, we describe how our proposal for a TLI system fits within the ILO's supervisory and monitoring activities.

The main initiative of the ILO aimed at MNEs directly is the Tripartite Declaration for MNEs, which is complemented by a Helpdesk for Business on International Labour Standards (further: the Helpdesk). ${ }^{110}$ The Helpdesk is run by MULTI (Multinational Enterprises and Enterprise Engagement Unit), whose key actions include running the Helpdesk; capacity building and training; "research and country-level assistance on topic areas of the MNE Declaration"; and "[p]romotion of the MNE Declaration among governments, employers and workers and the business community through collaboration with international organizations". 111 The Helpdesk is described as a "one-stop shop for company managers and workers on how to better align business operations with international labour standards and build good industrial relations".112 Additionally, the Helpdesk can offer a neutral place to MNEs and trade unions when they want to discuss issues of mutual concern, as well as provide input for the dialogue as a technical or expert adviser, and facilitate the dialogue itself. ${ }^{113}$ If necessary or so desired, the Helpdesk can "identify and maintain a list of qualified facilitators, and provide support to ensure that they execute their functions effectively".114

Interesting elements to highlight with respect to our proposal are MULTI's task for capacity building and training and the Helpdesk's option to "identify and maintain a list of qualified facilitators". For us, these are indications that how we envisage a TLI system embedded within the ILO is not so very far and different from what the ILO is actually already doing; especially since our TLI proposal would require the ILO to compile and maintain a list of labour inspectors that are either trained by the ILO itself or by an organization recognised or accredited by the ILO.

\footnotetext{
110 ILO, ILO Helpdesk for Business on International Labour Standards <https://www.ilo.org/ empent/areas/business-helpdesk/lang--en/index.htm>.

111 ILO, Multinational Enterprises <https://www.ilo.org/empent/units/multinational -enterprises/lang--en/index.htm>.

112 Ibid.

113 In public international law these activities qualify as 'offering good offices', which is considered as a form of diplomatic dispute settlement. Malcom N Shaw, International Law (Cambridge University Press 2003) 767, 770.

114 Annex II to the MNE Declaration (2011) s2.
} 
These are two elements that are clearly not alien to the activities already employed by the ILO. ${ }^{115}$ Moreover, these activities have been embraced by the ILO itself according to its own statement made during the second session of the OEIWG: capacity building and awareness-raising in public and private sectors are provided by the ILO to implement ILS and combat abuses in transnational operations. Special attention is given to government capacity to ensure inspection and enforcement, remedy and redress, by bolstering not only inspectorate knowledge and capacity, but also that of the law-makers and those who exercise justice through activities with parliamentarians and the judiciary. ${ }^{116}$

Hence, the training and accreditation of 'transnational' labour inspectors as well as facilitating a list of TLIs would be just one small step beyond the current activities of the ILO in relation to the training of national labour inspectors.

What is rather uncharted territory is the idea of establishing a system (ie the TLI) that fulfils a function (ie inspection), which traditionally has remained national. As we indicated in section 2 where we reviewed our proposal, the monitoring by the TLI will be complementary to national inspectorates. More particularly, the TLI activities will be limited to the commitments MNEs adhere to in their TPLI, eg CSR code of conduct. That there is also a need for such complementary publicly rooted monitoring at transnational level is clear from the, sometimes experimental and embryonic, examples we described in section 3. That it should be the ILO to facilitate such a TLI function seems simply logical given the fact that the ILO is already involved with a few of them, especially in the role of 'guarantor of neutrality', eg the Bangladesh Accord and the ILO's own Better Work Programmes. Moreover, embedding the TLI system would enable the ILO to align its inspection involvements and as such make this part of its activities more visible. Also, combining the experience of the various inspection activities would foster the harmonization and professionalization of these activities. As such the TLI would not only extent the ILO's toolkit with an additional tool to ensure compliance with labour standards, it

115 See for an example of a training programme related to CSR and due diligence: ILO, International Labour Standards and Corporate Responsibility: Understanding Workers' Rights in the Framework of Due Diligence (October 2018) <https://www.ilo.org/empent/Eventsandn meetings/WCMS_624284/lang--en/index.htm>.

116 ILO submission for the 2nd session of the Open-Ended Intergovernmental Working Group on Transnational Corporations and other Business Enterprises with respect to human rights(OHCHR, 2016) 10. 
would also offer the ILO a forum to professionalize its own inspection activities.

The TLI not only fits well within the ILO's activities regarding MNEs specifically, it also fits well within the ILO's more general supervisory and monitoring activities. We would not go as far as to propose that the TLI system would become part of the ILO's hard core supervisory mechanism, such as the regular system of supervision, and the special procedures. Similar to Van der Heijden and Zandvliet, ${ }^{117}$ we would instead argue that it could become an additional or complementary instrument to these mechanisms. More particularly, the TLI could be considered as an extra instrument in the ILO's broader toolkit to foster compliance with the labour standards, which besides the supervisory mechanisms also includes General Surveys, and Technical Assistance and Training. Via the General Surveys the ILO "examine[s] the impact of Conventions and Recommendations"; "analyse[s] the difficulties indicated by governments as impeding their application"; and "identifie[s] means of overcoming these obstacles". ${ }^{118}$ Technical Assistance and Training includes various activities via which ILO officials (or other experts) offer countries help to implement and comply with the obligations under ratified Conventions. More particularly, Technical Assistance includes activities such as advice, direct contact missions, and promotional activities like seminars and workshops. ${ }^{119}$ Training is provided by the ILO's International Training Centre (ITC) in Turin. The trainings are offered for, among others, government officials (including labour inspectors $)^{120}$ and employers. ${ }^{121}$ More generally, as part of technical assistance the ILO employs officials, but also can supply "other experts", and the training provided by the ITC in Turin includes trainings for labour inspections as well as MNEs interested in CSR and due diligence. Thus, again we can conclude that the activities of the ILO required to facilitate a publicly rooted TLI system is not completely alien to what is already custom to the ILO. Also in this wider toolkit of the ILO, we can see that the TLI would complete the three-legged model to ensure compliance with labour rights. The ILO's supervisory activities could be considered as a form of ADR (first leg). The technical assistance and training activities could be regarded as the second leg of enforcement,

117 See section 2 and $\mathrm{n} 31$.

118 See eg ILO, Applying and Promoting International Labour Standards <https://www.ilo. org/global/standards/applying-and-promoting-international-labour-standards/lang--en/ index.htm $>$.

119 Ibid.

120 See $<$ https://www.itcilo.org/> for an impression of courses for inspectors.

121 Ibid for examples of trainings for MNEs on CSR. 
namely awareness raising about rights and obligations. The TLI would form the third leg: inspection.

When we review the embedding of the TLI within the ILO from an international law point of view we can conclude the following. As we explored in section 4, there exists the status quo that MNEs have limited ILP, in particular when it comes to their responsibility in CSR matters, which creates legitimacy for international organizations to set standards (subject normation). Turning to the TLI system and the ILO, this means that there are no obstacles for the ILO to more consciously and strategically develop its inspection activities. The ILO is already active when it comes to the training of inspectors, both with national legislation as well as regarding the monitoring of CSR policies. Furthermore, the ILO is already involved with transnational inspection activities to ensure neutrality and credible monitoring with the Bangladesh Accord and its' own Better Work Programmes. As argued before, the TLI would not only be an additional instrument in the ILO's toolkit to ensure compliance with labour standards, it could also be a forum to further develop and professionalize its own (transnational) inspection activities, which we took as one of the important elements from the examples we discussed in section $3 .{ }^{122}$

To conclude, there are no general technical-legal obstacles for the ILO to embed a TLI system since it is generally accepted that MNEs possess ILP in relation to their responsibility in CSR matters. Not only does the ILP of MNEs in these matters legitimises subject normation activities by the ILO, as presented in section 4, there are also persuasive material arguments for the ILO to do so. Furthermore, given the already existing activities of the ILO, the activities required to embed and facilitate the TLI system as we envisage it, especially to comprise and maintain a list of accredited TLIs and to train potential TLIs, are not alien at all to the ILO. More institutionally there are two settings within the ILO in which the TLI could fit perfectly: within the Helpdesk which is run by MULTI, or as additional instrument to the ILO's supervisory mechanism and its Technical Assistance and Training activities that are part of the ILO's general toolkit to enforce compliance with the labour standards. In both institutional settings the TLI would complement the ILO's existing activities with the 'third leg' to ensure compliance: awareness raising; (alternative) dispute settlement; and inspection. Additionally, embedding the TLI would enable the ILO to further develop and professionalize its own inspection activities. Setting aside the political feasibility of the embedding of the TLI within the ILO, the proliferation of various publicly rooted forms of transnational

122 See especially the example of the NCPs and considerations about the ELA. 
monitoring we described in section 3 , the fact that there are no technical-legal obstacles to set up a TLI as explored in section 4, and in light of the already existing activities of the ILO explored in this section, it seems just a matter of seizing the right moment to make it happen. 